\title{
Adverse Event Outcome
}

National Cancer Institute

\section{Source}

National Cancer Institute. Adverse Event Outcome. NCI Thesaurus. Code C49489.

A condition or event that is attributed to the adverse event and is the result or conclusion

of the adverse event. 